FETAL AND NEONATAL EDITION

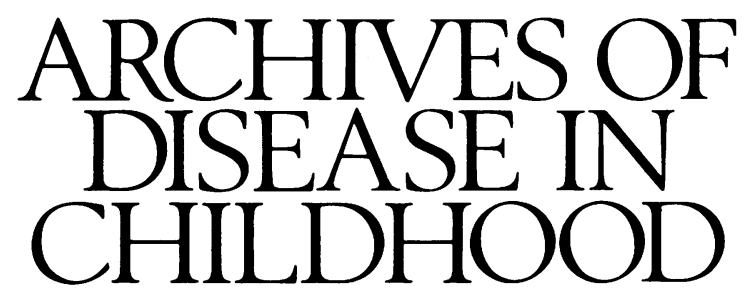

The fournal of the British Paediatric Association

\title{
Management of suspected tracheobronchial stenosis in ventilated neonates
}

Both bronchography and balloon dilatation are often absent from the management plan of most units dealing with suspected neonatal tracheobronchial stenosis (TBS), despite several previous favourable reports. This may be due to medical inertia, to changes in practice, or to real issues about the safety and efficacy of these complementary techniques.

In the paper on page F3, 13 cases of TBS involved the lower trachea and bronchus and were probably caused by tube tip ulceration and deep suction. This is a different disease from the more commonly seen subglottic (laryngotracheal) stenosis which is probably of an acquired on congenital aetiology. The 13 cases of TBS were from a total of 1002 ventilated babies. This incidence compares with those of other series, but it does not include cases of subglottic stenosis. However, only one case of stenosis was mild and self limiting, so it does not seem that bronchography was oversensitive and was itself responsible for this high figure.

\section{Diagnosis}

The authors list the radiological and clinical pointers for suspicion of TBS, though it is often not discovered until endoscopy for failure to extubate. Bronchography is one of a number of available techniques which all have advantages and drawbacks.

\section{BRONCHOGRAPHY}

The instillation of small amounts of non-ionic contrast medium does not seem to be associated with broncho- spasm or oxygen desaturation, and despite the iodine content does not affect thyroid function. It would thus seem to be safe, as described before. ${ }^{2-5} 7$

In these studies the radiological results correlated well with the endoscopic or postmortem findings. Riebel found the trachea and main bronchi to be well demonstrated in all procedures, though the lobar and segmental bronchi were not always seen adequately. ${ }^{2}$

\section{RIGID ENDOSCOPY 6}

Paediatric bronchoscopy can be challenging for both surgeon and anaesthetist, but modern optics permit superb visualisation and an ability to appreciate how firm a stenosis is by gentle dilatation. The exact site of any pulsation can be seen and complete cartilaginous rings demonstrated, if present. Video printers have revolutionised documentation. Neonatal laryngoscopy is possible in the neonatal unit, ${ }^{8}$ but atraumatic rigid bronchoscopy requires operating theatre facilities.

With tight stenoses a combination of rigid and fibreoptic bronchoscopy may be needed.

\section{FIBREOPTIC BRONCHOSCOPY}

With smaller, brighter, and clearer endoscopes, fibreoptic examination may become a safe and effective way of demonstrating the tracheobronchial tree in the neonatal unit.

Overall, if neonatal units have ready access to a high quality bronchoscopy service, this offers most information. If transfer to a second institution is necessary,

Advantages and drawbacks of available techniques

\begin{tabular}{lll}
\hline & Advantages & Disadvantages \\
\hline $\begin{array}{l}\text { Plain } x \text { ray picture } \\
\begin{array}{l}\text { Penetrated A-P } \\
\text { (Cincinnati) }\end{array}\end{array}$ & Routine and available in unit & May implicate but rarely demonstrates stenosis \\
$\begin{array}{l}\text { Fluoroscopy } \\
\text { ECHO/CT/MRI }\end{array}$ & $\begin{array}{l}\text { Can delineate stenosis } \\
\text { ?Gold standard for dynamic assessment if coupled with } \\
\text { alteration in CPAP } \\
\text { Useful for extrinsic compression } \\
\begin{array}{l}\text { In unit. Demonstrates pathology beyond stenosis } \\
\text { Rigid endoscopy }\end{array}\end{array}$ & $\begin{array}{l}\text { Needs high KV/filter. Tube can occlude stenosis } \\
\text { May need to leave unit }\end{array}$ \\
$\begin{array}{l}\text { Flexible endoscopy } \\
\text { Full characterisation of lesion - can combine with dilatation } \\
\text { Can be undertaken in unit. Can pass tight stenoses }\end{array}$ & $\begin{array}{l}\text { Need to leave unit. Cost } \\
\text { Unable to differentiate hard from soft stenosis. Only two dimensional. } \\
\text { Cannot identify complete rings } \\
\text { Needs surgical and anaesthetic expertise to be safe. Need to go to theatre } \\
\text { Lower quality image than rigid }\end{array}$ \\
\hline
\end{tabular}


bronchography seems to offer a safe alternative to diagnose stenoses.

\section{Treatment of TBS}

Severe established low tracheal and bronchial stenosis, when it occurs in premature neonates, has a poor outcome. There is no single effective treatment and because of the small number of reported cases with varying pathology, comparing the outcomes of different techniques is difficult. Basically there are four techniques available: dilatation; stenting; augmentation; and resection.

\section{DILATATION}

Gentle dilatation can be effective in immature stenoses, but the forceful dilation required in established fibrous stenosis and in congenital complete cartilaginous rings carries a high risk of tracheal or bronchial rupture as seen in this series. Balloon dilatation has the theoretical advantage of only exerting radial forces to the stenosis which should therefore cause less disruption to the mucosal lining. ${ }^{9}$ The feared complication of tracheal or bronchial rupture, however, may still occur. ${ }^{1011}$ Inflation with a syringe can be calibrated in terms of volume and pressure, but the system lacks the direct 'feel' which is possible when using bougies down a rigid bronchoscope.

\section{STENTING}

Dilatation followed by insertion of an indwelling stent is an effective means of maintaining an expanded stenosis but the stent acts as a foreign body and inhibits mucociliary clearance. This leads to increased secretions, infection, granulations and eventually stent blockage. ${ }^{12}$ A further problem is that the stenosis tends to squeeze the stent and dislodge it. This is more of a problem with siliconised plastic stents than with expandable metal stents. The latter may develop granulations late and then be difficult to remove. Low and midtracheal stenoses can be managed with a specially extended tracheostomy tube passed through the stenosis, though the natural movement of the tube on head flexion and extension tends either to impact the tube on the carina or to allow the tube to ride up above the stenosis.

\section{AUGMENTATION}

Cartilage grafts are commonly used in subglottic (laryngotracheal) stenoses with a success rate of $80-90 \%$. Cartilage grafts in lower tracheal and bronchial lesions have particular problems. ${ }^{1314}$ The surgery is more difficult to stent and any air leak is more serious. Pericardial patches ${ }^{15} 16$ have been used in a number of series but do not have the support of more rigid materials. A stenotic segment can thus be replaced by a malacic segment.

\section{RESECTION}

If the stenosis is short, as often occurs with a tube tip stenosis, then resection and end to end anastomosis is relatively straightforward, incorporating a laryngeal drop and hilar release if necessary. ${ }^{17}$ When restenosis occurs at the anastomotic site, management is more difficult as the trachea is now short as well as stenotic. In oesophageal tracheoplasty mucosalisation of the trachea does not seem to be a problem. ${ }^{18}$ Tracheal resection followed by cadaver tracheal transplantation or live donor heart-lung transplantation are feasible procedures to consider if other options have been exhausted.

\section{Discussion}

Acquired tracheobronchial stenosis in ventilated neonates should be avoidable by careful suction and tube placement and fixation. Diagnosis, though often suspected on plain radiographs, is fully demonstrated after bronchoscopy. Bronchography offers a safe alternative which can be achieved on the unit.

Treatment may not be necessary for mild lesions which can resolve spontaneously. Even with moderate lesions the risks of any procedure have to be balanced against the continuing ventilatory difficulty of treating the stenosis conservatively. In severe stenoses where treatment is clearly required a dilatation procedure is a sensible first option as the soft tissues of the neonatal airway may be more amenable to dilatation than in older children and adults. In the absence of hard evidence the choice between rigid and balloon dilatation will depend on local experience. Open surgery should be offered by a few centres only so that experience can be concentrated and prognosis improved.

34 Great Ormond Street,

D ALBERT

London WC1 $37 H$

1 Vogl VT, Wilimzig C, Bilaniuk LT, Hofmann U, Hofmann D, Dresel S, et al. MR imaging in pediatric airway obstruction. 7 Comput Assist Tomogr $1990 ; 14: 182-6$

2 Riebel T, Wartner R. Use of non-ionic contrast media for tracheobronchography in neonates and young infants. Eur f Radiol 1990; 11: 120-4.

3 Bramson RT, Sherman JM, Blickman JG. Pediatric bronchography performed through the flexible bronchoscope. Eur $\mathcal{F}$ Radiol 1993; 16: performed

4 Tuma S, Zabrodsky V, Povysilova V, Kanta J, Brezovsky P, Ost'adal B, et al. Tracheobronchography in neonates and infants with obstruction of the upper respiratory tract. Cesk Radiol 1990; 44: 247-52.

5 Oh KS, Newman B, Bowen A, Bender TM. Pediatric airway disorders: practical approaches to imaging evaluation. Curr Probl Diagn Radiol 1989; 18: $211-2$.

6 Hoeve LJ, Rombout J. Pediatric laryngobronchoscopy. 1332 procedures stored in a data base. Int $\mathcal{f}$ Pediatr Otorhinolaryngol 1992; 24: 73-82.

7 Rivron A, Treguier C, Bourdiniere J, Grimaux B, Le Clech G, Bétrémieux $\mathrm{P}$, et al. Les stenoses tracheo-bronchiques acquises du premature ventile interêt de la bronchographie et de la dilatation endoscopique au ballonnet; à propos de 7 cas. Ann Otolaryngol Paris 1992; 109: 1-5.

8 Albert DM, Mills RP, Fysh J, Gamsu H, Thomas JN. Endoscopic examination of neonatal larynx at extubation: a prospective study of variables tion of neonatal larynx at extubation: a prospective study of variables associated

9 Hebra A, Powell DD, Smith CD, Biemann Othersen H Jr. Balloon tracheoplasty in children: results of a 15-year experience. $\mathcal{F}$ Pediatr Surg 1991; 26: 957-61

10 Messineo A, Forte V, Joseph T, Silver MM, Filler RM. The balloon posterior tracheal split: a technique for managing tracheal stenosis in the premature infant. $\mathcal{F}$ Pediatr Surg 1992; 27: 1142-4.

11 Bagwell CE, Talbert JL, Tepas III JJ. Balloon dilation of long-segment tracheal stenoses. 7 Pediatr Surg 1991; 26: 153-9.

12 Mair EA, Parsons DS, Lally KP. Treatment of severe bronchomalacia with expanding endobronchial stents. Arch Otolaryngol Head Neck Surg 1990; 116: $1087-90$.

13 Kimura K, Mukohara N, Tsugawa C, Matsumoto Y, Sugimara C, Murata $\mathrm{H}$, et al. Tracheoplasty for congenital stenosis of the entire trachea. 7 Pediatr Surg 1982; 17: 869-71.

14 Van Meter CH, Lusk RM, Muntz H, Spray TL. Tracheoplasty for congenital long-segment intrathoracic tracheal stenosis. Am Surg 1991; 57: 157-60.

15 Cosentino CM, Backer CL, Idriss FS, Holinger LD, Gerson CR, Mavroudis C. Pericardial patch tracheoplasty for severe tracheal stenosis in children: intermediate results. $\mathcal{f}$ Pediatr Surg 1991; 26: 879-84.

16 Idriss FS, DeLeon SY, Ilbawi MN, Gerson CR, Tucker GF, Holinger L. Tracheoplasty with pericardial patch for extensive tracheal stenosis in infants and children. 7 Thorac Cardiovasc Surg 1984; 88: 527-36.

17 Longaker MT, Harrison MR, Adzick NS. Testing the limits of neonatal tracheal resection. $\mathcal{F}$ Pediatr Surg 1990; 25: 790-2.

18 Sasaki S, Hara F, Ohwa T, Eguchi T, Masaoka A. Esophageal tracheoplasty for congenital tracheal stenosis. $\mathcal{F}$ Pediatr Surg 1992; 27: 645-9. 